\title{
Short Communication: Roosting behavior of Wintering Barn Swallow (Hirundo rustica) in Peninsular Malaysia
}

\author{
NOR ADIBAH ISMAIL, ABDILLAH BAGIR ABDUL KADIR AL JUFRI, UMMI NUR SYAFIQAH DAUD, \\ SHUKOR MD. NOR, MOHAMMAD SAIFUL MANSOR \\ Department of Biological Sciences and Biotechnology, Faculty of Science and Technology, Universiti Kebangsaan Malaysia. 43600 UKM Bangi, \\ Selangor, Malaysia. Tel.: +60-3-8921 6179, ^email: msaifulmansor@gmail.com, dibahismai196@gmail.com
}

Manuscript received: 1 December 2019. Revision accepted: 20 January 2020.

\begin{abstract}
Ismail NA, Al Jufri ABAK, Daud UNS, Md. Nor S, Mansor MS. 2020. Short Communication: Roosting behavior of Wintering Barn Swallow (Hirundo rustica) in Peninsular Malaysia. Biodiversitas 21: 661-665. The East Asian Barn Swallow Hirundo rustica gutturalis primarily breeds in China, Japan, and Korea, typically migrates to Southeast Asia during winter, including Malaysia. To date, knowledge regarding population of Barn Swallow is limited to their breeding grounds and other subspecies (e.g., European Barn Swallow Hirundo rustica rustica). A previous study on Barn Swallow wintering in Malaysia was conducted approximately 50 years ago and mainly focused on population dynamics. The objective of the present study was to investigate the roosting behavior of wintering Barn Swallows in a major roosting site, Bentong, central Peninsular Malaysia, from October 2018 to March 2019. Scan sampling at 5min intervals was used to examine the roosting behavior of the swallows perching on service wires (i.e., electricity and telephone wires). We found that the swallows began to roost an average of 10 minutes after sunset and slept 55 minutes later. However, cloudy and rainy weather significantly affects swallow roosting period, leading them to perch earlier, 5 minutes before sunset. The pattern of roosting behavior was somewhat similar throughout the migration season, except in the early migration season (October), which was likely inconsistent due to their early adaptation to the town environment. Behavioral scan sampling revealed that swallows spend most of the time motionless, followed by preening. However, anthropogenic disturbances disrupt their behavior and sleep time. We also noted that this communally roosting bird behaved gregariously on wires, particularly at sites illuminated by light, which is likely an anti-predator mechanism.
\end{abstract}

Keywords: Behavior, East Asian Barn Swallow, migratory, resting, tropical region

\section{INTRODUCTION}

The Barn Swallow Hirundo rustica is a widespread species that successfully breed in human settlements (Scordato and Safran 2014). There are six subspecies of $H$. rustica in total. Notably, H. r. savignii breed in North Africa, while the breeding and wintering range of $H$. $r$. transitiva is heavily restricted within the Middle East. Furthermore, $H$. r. rustica breed in Europe and H. r. tytleri breed in Siberia and Mongolia, while H. r. gutturalis breed in East Asian nations such as China, Japan, and the Korean peninsula. Finally, H. r. erythrogaster breeds in North America (Del Hoyo et al. 2018). Barn Swallows on passage or wintering in Peninsular Malaysia are largely identified as H. r. gutturalis (Wells, 2007).

As a colonial bird, the Barn Swallow's preferred habitat during the breeding season is in low-lying open fields and livestock farms whereas, in winter, their preferred areas are usually near rivers and lakes (Curry-Lindahl 1963; Nutall 2000). Barn Swallows typically locate opportunities for aerial feeding throughout the region, including in urban areas such as old towns or villages, rural areas such as parks, agricultural areas, as well as around lakes and rivers (Peck and James 1987; Turner 1994). This Barn Swallow's population appears to roost along service wires (electricity and telephone wires) in urban areas such as the old town like Bentong - a behavior that can also be observed in their temperate breeding and wintering regions (Verma 2010). A study by George (1965) from Mumbai, India, stated that, apart from sugarcane and mangrove swamps, thousands of Barn Swallows in a specific area also chose service wires as their main roosting place. During the migration season, Medway (1973) stated that Barn Swallows in Peninsular Malaysia preferred to roost on service wires instead of roofs, ledges, billboards, and windows. Notably, the gaps between individuals choosing a service wire as a breakpoint were more coordinated as the bird population increased. Once these birds filled the spaces along the lines of illuminated service wires, the remaining colonies chose other areas such as roofs, ledges, windows, and shop signs.

Most ecology studies on Barn Swallows have focused on their breeding grounds, while fewer studies related to passage and wintering grounds have been performed. The last swallow study in Peninsular Malaysia was conducted nearly half a century ago by Medway (1973) and was largely focused on population dynamics. Hence, the study aims to examine the roosting behavior of wintering Barn Swallows in a major roosting town in central Peninsular Malaysia. 


\section{MATERIALS AND METHODS}

\section{Study area}

The study was conducted in the town area of Bentong, Pahang, central Peninsular Malaysia. The town is $80 \mathrm{~km}$ north-east of Kuala Lumpur and opposite the Titiwangsa Range. The area of Bentong is $1831 \mathrm{~km}^{2}$, and it borders the State of Selangor on the west and Negeri Sembilan on the south. Bentong District was managed by the Bentong Municipal Council Administration and is divided into three mukims, namely Bentong Mukim, Sabai Mukim, and Pelangai Mukim.

\section{Procedures}

The present study was conducted in the early evenings during the migration season, from October 2018 until March 2019. The weather data was acquired from Malaysian Meteorological Department. Observations were performed by only one observer to reduce bias at selected service wires in the town using a modified scan sampling method at 5-minute intervals following Altmann (1974),
Martin and Bateson (1993), and Samson and Ramakrishnan (2016). Only the initial behaviors (i.e., the first sighting of an individual bird) were recorded to avoid problems related to non-independent data (Mansor and Ramli 2017; Mansor et al. 2018a). Subsequent observations of foraging in the same bird were assumed to be correlated and were thus ignored (MacNally 1994).

Observations were performed at selected services wires linking many electric posts. Generally, roosting swallows perched side by side to form a neat line along the wire that with a length of over 10 meters. Only ten individuals were chosen per observation, and all observed individuals had a certain distance from neighboring birds to ensure that their behavior was free from their neighbor's influence. All observations began when the sun began to set. The time at which the first bird perched was also recorded. Behavioral observations were only conducted when the colony grew to at least ten individuals and every behavioral activity was observed from the first perch until they fell asleep.
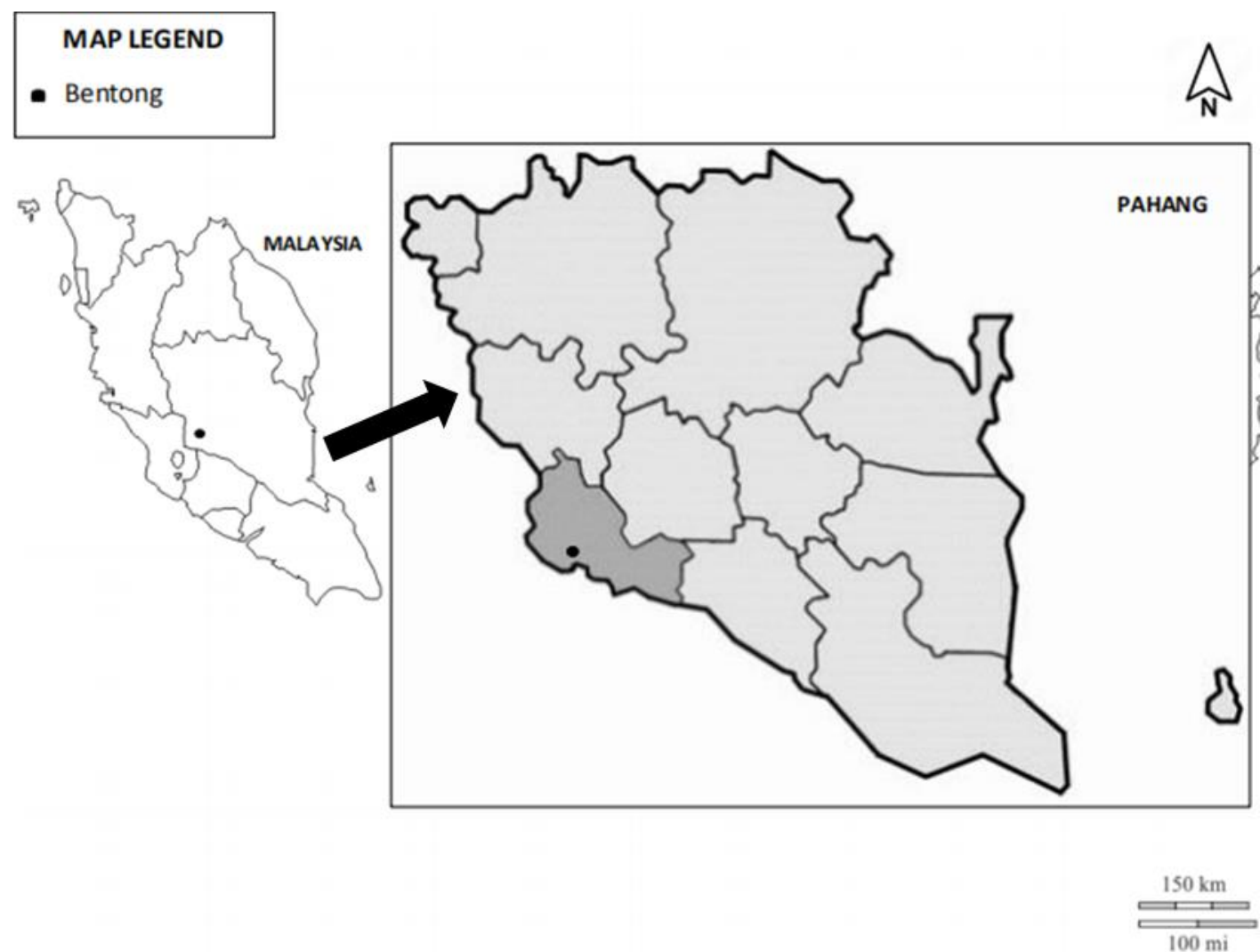

Figure 1. Location of Bentong town, indicating the sampling sites of Hirundo rustica gutturalis 
The roosting behavior classification was performed using a modified classification method following Ramji et al. (2013) during the period of roosting prior to sleep. The classifications include: (i) stationary - the bird does not exhibit major movement from limb, only subtle movement from the head; (ii) socializing - the bird chirps with adjacent birds on both sides; (iii) site shifting - the bird shifts to a nearby place on the same line; (iv) leaving - the bird flies to another site beyond the observer's sight; (v) territorial behavior - (a) attacking (an individual initiates aggression by snapping and lunging its beak while hovering with its wing fluttering rapidly to harass another individual that possesses a roosting spot, usually performed by a bird flying in searching of roosting spot) or (b) retaliating (prompted by the aforementioned harassment, where birds react with a similar behavior, i.e., by snapping its beak, rapidly fluttering its wings - but not lunging to ward off the attacker); (vi) preening - the bird uses its beak to clean off feathers of the neck, dorsal side, ventral torso and flight feathers found on the wings and tail; (vii) lineassembling - a non-flight movement involving strolling or hopping sideways to be in close proximity to adjacent birds, as most swallows do not leave a large space between them; (viii) defecating - defecating while roosting prior to sleep. Finally, swallows are said to sleep when they tuck their heads into the feathers of their ventral side (Medway 1973).

\section{Data analysis}

Principal component analysis (PCA) was performed using PRIMER-E version 7 (Clarke and Gorley 2015). It was to determine the roosting behavior of swallows. We used a scree plot to define the components of all behavior parameters in the analysis, and only components with eigenvalues $>1$ were selected. From each of the components, high loading plots were used to determine significant parameters (e.g., assembling and socializing).

\section{RESULTS AND DISCUSSION}

A total of 100 individuals of swallow were observed in present study, with average of 2 hours per observation starting from the first perch at sunset till they fell asleep (no movement). The present study also found that the roosting behavior pattern of wintering Barn Swallows in a town of central Peninsular Malaysia was similar throughout the migration period, with stationary and preening being the most prominently observed behaviors (Figure 2). Stationary behavior involves the swallows remaining nearly motionless (except for minor head-turning and tilting in order to observe their surroundings) or not making any movement at all. Meanwhile, preening involves cleaning feathers with their beak from time to time. However, during the early migration season, particularly in October, other behaviors (e.g., leaving, assembling) were also displayed by swallows, which were probably due to some new arrivals still attempting to adapt to their new locations in search of a preferred roosting site. Furthermore, most swallows in the area seemed to be disturbed by a variety of sounds from passing vehicles.

The PCA of barn swallow roosting behavior yielded two components that explained $94 \%$ of the variation (Figure 3). The first principal component explained $79 \%$ of the variation that was weighted on the stationary behavior (V4), whereas the second component explained $15 \%$ of the variation that was weighted on preening (V5). The selected components were based on a scree plot curve and the range of percentages between components. In this case, the range of percentages between component 2 and component 3 was too small; therefore, only two (instead of three) components were selected for an explanation.

We determined that the arrival time for swallows to perch on service wires was proportionate to sunset duration (Figure 4). The longer it took for the surrounding area to become darker, the later the swallows roosted. Some individuals were seen perching when the sky was completely dark and was subsequently followed by thousands of other birds. Moreover, we found that the weather strongly influenced swallow roosting time. The average time at which swallows perched on a wire was 10 minutes after sunset under normal conditions (Mean temperature: $27.4^{\circ} \mathrm{C}$, rainfall amount: $1.0 \mathrm{~mm}$ ); however, they perched earlier (before sunset) during cloudy and raining conditions in November (Mean temperature: $26.3^{\circ} \mathrm{C}$, rainfall amount: $21 \mathrm{~mm}$ ). Smiddy et al. (2007) made a similar observation of swallows beginning to roost when the sky became dark or when insects were scarce. It was reported that the weather has a significant influence on the roosting behavior of swallows, in which the rain and low temperatures will force the birds to roost earlier on wet evenings (Giller 1955; Loske 1984; Winkler 2006). The present study also found that the average sleeping time for swallows was 1 hour and 55 minutes, which was earlier in the first four months of the study and delayed in the later dark-sky period. In January, swallows roosted significantly later than in the other months (relative to sunset). Pressure on food may cause birds to feed later, but this is unlikely in this case as the total amount of daylight available for feeding in January (approximately 10hr/day) was higher than in October (approximately $7 \mathrm{hr} /$ day), November (approximately 6hr/day), and December (approximately 3 hr/day). The lower proportion of overcast and breezy evenings (Mean temperature: $28.1^{\circ} \mathrm{C}$, rainfall amount: 0 $\mathrm{mm}$ ) recorded in January could be a contributing factor to this situation.

We noted that roosting swallows were more likely to choose a roosting place illuminated by lights, which was likely done to improve the potential to defend against predators such as owls. Notably, Verma (2010) stated that lights could also provide heat for the birds, while insects attracted to lights around the roosting area can become a primary food source for swallows. 


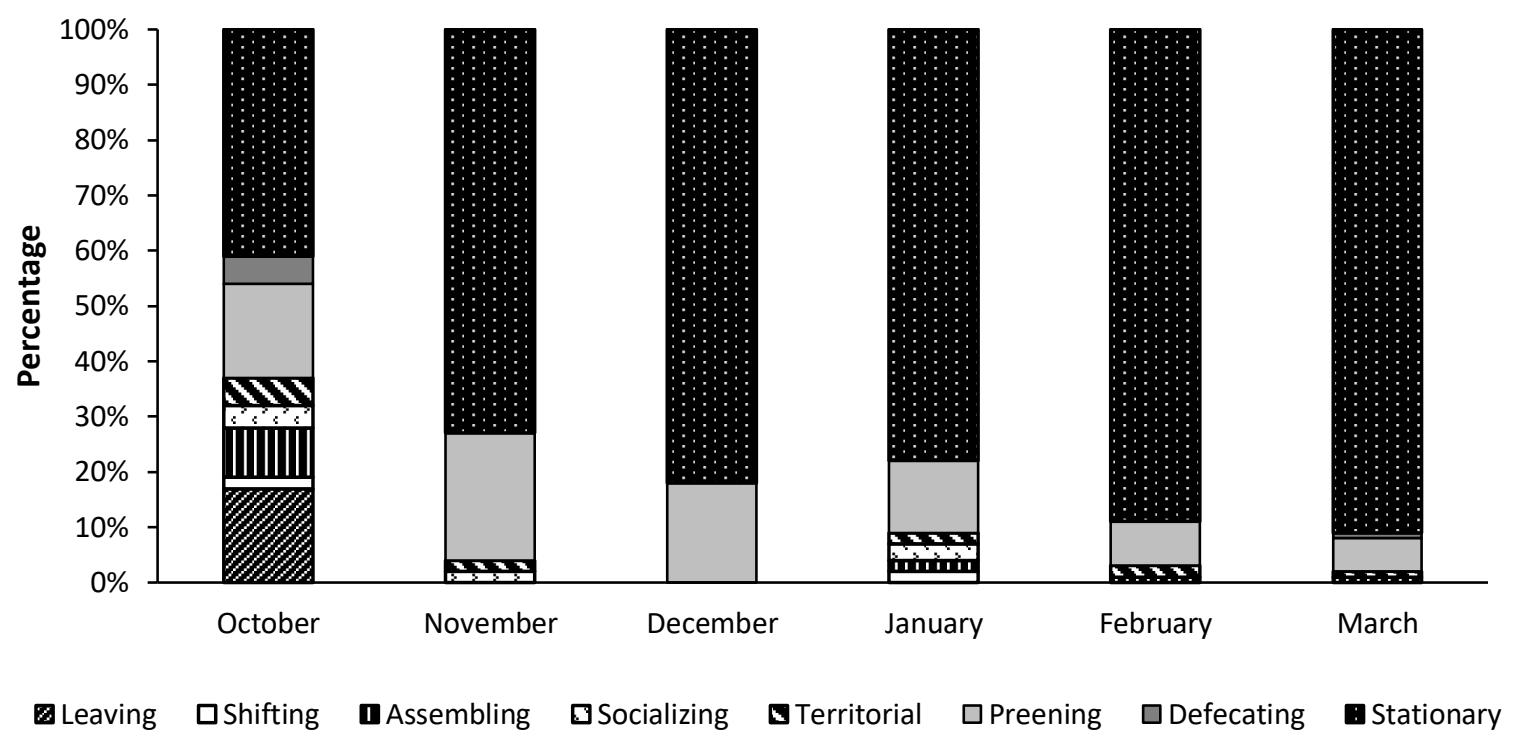

Figure 2. Variation in roosting behavior percentage displayed by swallows prior to sleep (by month)

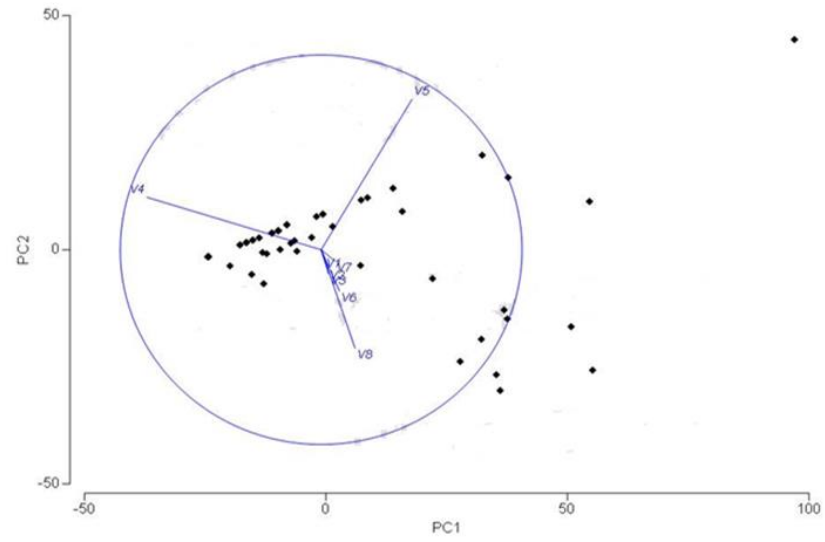

Figure 3. Distribution of observed swallows according to behavior type based on the principal component analysis. Abbreviations: V1 = shifting; V2 = socializing; V3 = defecating; $\mathrm{V} 4=$ stationary; $\mathrm{V} 5=$ preening; $\mathrm{V} 6=$ assembling; $\mathrm{V} 7=$ territorial; V8 = leaving.

In conclusion, service wires favored by the roosting swallows should be considered and maintained in Bentong town management planning or any other towns occupied by swallows. In addition, we suggest that future research should extend this study by identifying the stopping-over sites along East Asian-Australasian Flyway as well as aerial insects consumed by this migrant species in wintering regions (Mansor et al. 2018b).

\section{ACKNOWLEDGEMENTS}

We are grateful to the Universiti Kebangsaan Malaysia Research Fund [GUP-2018-019], which provided financial support for this study. We thank the Department of

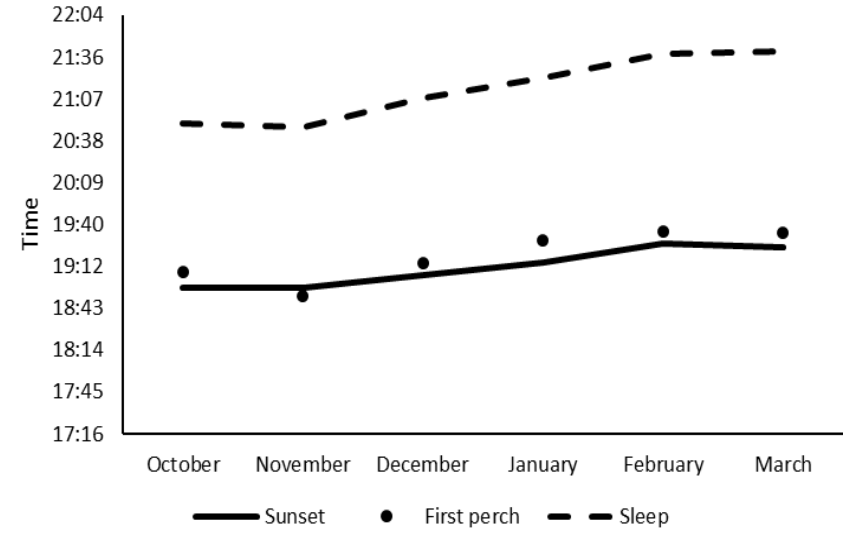

Figure 4. Time of sleeping (dashed line), time of sunset (solid line), and time of first perching (dot) of Barn Swallow at Bentong town, Pahang.

Wildlife and National Parks for their permission to perform this research. We also thank Nur Asyikin Rosli for her assistance in the field.

\section{REFERENCES}

Altmann J. 1974. Observational Study of Behavior: Sampling Methods. Behaviour 49 (3/4): 227-267.

Curry-Lindahl K. 1963. Roosts of Swallows (Hirundo rustica) and House Martins (Delichon urbica) during the migration in tropical Africa. Ostrich 34: 99-101.

Clarke KR, Gorley RN. 2017. PRIMER v7: User Manual/Tutorial. PRIMER-E: Plymouth, United Kingdom.

Del Hoyo J, Elliott A, Sargatal J, Christie D. 2018. Handbook of the Birds of the World Alive. Lynx Edicions, Barcelona, Spain. 
George PV. 1965. Swallows Hirundo rustica Linnaeus roosting on wires J Bombay Nat Hist Soc 62: 160.

Giller F. 1955. Beobachtungen an einem Rauchschwalbenschlafplatz. Vogelwelt 76: 180-184.

Loske KH. 1984. Observations On the Swallow Hirundo-Rustica At Mass Roosting Places in the Middle of North-Rhine-Westphalia West Germany. Vogelwelt 105: 51-60.

MacNally R. 1994. Habitat specific guild structure of forest birds in South-Eastern Australia: a regional scale perspective. J Anim Ecol 63: 988-1001.

Mansor MS, Abdullah NA, Halim MRA, Nor SM, Ramli R. 2018b. Diet of tropical insectivorous birds in lowland Malaysian rainforest. J Nat Hist 52: 2301-2316.

Mansor MS, Nor SM, Ramli R, Sah SAM. 2018a. Niche shift in three foraging insectivorous birds in lowland Malaysian forest patches. Behav Process 157: 73-79.

Mansor MS, Ramli R. 2017. Foraging niche segregation in Malaysian babblers (Family: Timaliidae). PLoS ONE 12 (3): e0172836.

Martin P, Bateson P. 1993. Measuring Behaviour. $2^{\text {nd }}$ Edition. Cambridge University Press, Cambridge.

Medway L. 1973. A ringing study of migratory Barn Swallows in west Malaysia. Ibis 115: 60-86.

Nutall RJ. 2000. European swallow roosts in the Memel District, Free State, South Africa. Mirafra 17: 57-58.
Peck GK, James RD. 1987. Breeding birds of Ontario: Nidiology and Distribution. Volume 2: Passerines. Life Sciences Miscellaneous Publications. Royal Ontario Museum, Toronto.

Ramji MFS, Koon LC, Rahman MA. 2013. Roosting and nest-building Behaviour of the white-nest Swiftlet Aerodramus Fuciphagus (Thunberg) (Aves: Apodidae) in farmed colonies. Raffles Bull Zool 29: 225-235.

Samson A, Ramakrishnan B. 2016. Observation of a population of Egyptian vultures Neophron perenopterus in Ramanagaram Hills, Karnataka, Southern India. Vulture News 71 (1): 36-49.

Scordato ESC, Safran RJ. 2014. Geographic variation in sexual selection and implications for speciation in the Barn Swallow. Avian Res 5: 8 .

Smiddy P, Cullen C, O'Halloran J. 2007. Time of roosting of Barn Swallows Hirundo rustica at an Irish reedbed during autumn migration. Ringing Migr 23: 228-230.

Turner AK. 1994. The Swallow. Hamlyn, London.

Verma SK. 2010. Population and roosting behaviour of Barn Swallows Hirundo rustica wintering in Jamshedpur, Jharkhand, India. J Threat Taxa 2: 721-723.

Wells DR. 2007. The birds of the Thai-Malay Peninsula. Vol. II, Passerines. Christopher Helm, London.

Winkler D. 2006. Roosts and migrations of swallows. Hornero 21 (2): 85 97. 